\title{
Effect of Delonix Regia (Flame Tree) as Biorodenticide in Eliminating Wistar Albino Rats
}

\author{
${ }^{1}$ Omaka Onyekachi and ${ }^{2}$ Nwajiobi Favour Okwukweka \\ ${ }^{1}$ Chief Research Consultant, Maeve academic Research Laboratory Awka, Anambra State, Nigeria \\ ${ }^{2}$ Department of Applied Microbiology and brewing,Nnamdi Azikiwe
}

University Awka Anambra State, Nigeria

\begin{abstract}
The study examined the effect of Delonix regia (flame tree) as biorodenticide in eliminating Wister albino rat. The plant samples used were collected from the Nnamdi Azikiwe university campus, dried for three days then the extract was extracted with the use of Soxhlet extractor using ethanol as extraction solvent after which the extract was concentrated in a rotary evaporator. The extract was administered to the wister Albino rate ate $200 \mathrm{mg} / \mathrm{ml}$ dose and $400 \mathrm{mg} / \mathrm{ml}$ dose. From the phytochemical analysis of the plant, the result showed that the plant contains phytochemicals such as steroids, alkaloid among others. The result also showed that the weight of the rat increased to $128.33 \pm 7.53^{b}$ when given treatment as compared to their body weight $\left(114.66 \pm 8.08^{a}\right)$ before treatment. The result further indicated that at $200 \mathrm{mg} / \mathrm{ml}$, the weight of the rat is statistically significant than that at $400 \mathrm{mg} / \mathrm{ml}$. From the analysis, it was noted that the organ weight of the rat and PCV of 200mg/ml dosage is higher $\left(43.66 \pm 4.48^{b}\right)$ than that $400 \mathrm{mg} / \mathrm{ml}\left(30.33 \pm 2.603^{a}\right)$ though this result is not statistically significant at $P>0.05 \%$. Comparing the relative organ weight of the rat at $200 \mathrm{mg} / \mathrm{ml}$ and at $400 \mathrm{mg} / \mathrm{ml}$, the weight at $400 \mathrm{mg} / \mathrm{ml}$ for liver(3.68\%) and kidney(0.79\%) is higher than $200 \mathrm{mg} / \mathrm{ml}$ relative liver weight $(3.55 \%)$ and kidney $(0.65 \%)$. The difference in the relative organ weight is also not statistically significant at $P>0.05 \%$. There were no toxicity effects of the extract observed on the rat neither were there any mortality. Therefore, the study recommended that pharmaceutical industries should harness the potential of Delonix regia extract in the production of drugs and use it in the control of obesity among the human population and little dosage of the Delonix regia extract can be also be used in others to boast and maintain packed cell volume.
\end{abstract}

Keywords: Comparative Study, Flame Tree, Biorodenticide, Eliminating, Wistar Albino \& Rats.

\section{INTRODUCTION}

\subsection{Background to the Study}

Rodents have gained the reputation as one of the most persistent and ubiquitous vertebrate pests affecting human populations. Rodent population outbreaks, which can occur cyclically (Singleton et al., 2010) can be particularly damaging. They cause economic problems because of the damage they inflict on agricultural systems (Singla and Babbar 2010) environmental problems due to the chemicals used for their control (Singleton and Redhead 1989), social problems associated with their close proximity to human habitation and health problems as several rodent pest species are also disease vectors. For example, house mice carry diseases (e.g., salmonellosis, leptospirosis) and therefore pose a health risk for humans, especially in urban areas (Cameron, 1949). The financial loss due to rodent-borne zoonoses is not known but may be similar to rodent derived losses in agriculture (Bonnefoy et al., 2008). Conventional pesticides possess inherent toxicities that endanger the health of the farm operators, consumers, and the environment.

The availability of efficient rodenticides is narrowing and most current approaches are focused on short-term reductions of ongoing damage without much attention to longer term effects. Popular anticoagulant rodenticides can have negative effects on non-target species and can also pollute the environment (Geduhn et al., 2014). They are usually classified as 'first generation' compounds, which act as chronic toxicants, requiring multiple exposures over a short period of time to be effective and have a relatively short half-life. More effective, 'second generation' compounds have a significantly higher-toxicity, and can be lethal after a single dose (Hadler and Buckle 1992). All anticoagulant rodenticides may cause primary (consumption of bait by target 
and non-target species) and secondary poisoning (non-target species consume poisoned prey). Sometimes farmers prefer acute poisons; these types of rodenticides have a lower risk of secondary poisoning of non-target wildlife and effects are readily visible (Singleton et al., 2007).

Resistance to both first and more recently to some of the second generation compounds is a phenomenon which has been known since the 1960s (Buckle et al., 1994) and is an increasing problem for the use of anticoagulants rodenticides in crop and health protection. Such negative effects of conventional pesticides on human health led to a resurgence in interest in botanical pesticides because of their minimal costs and fewer ecological side effects. Plant extracts have been used as pesticides by humans since before the time of the ancient romans, a practice that continues to the present time with many of the plant species known to have pesticide properties. The use of toxic plants is especially prevalent in the developing countries, where plants grown locally are cheaper than the synthetic chemical pesticides (Gabr, 2005). Plants with strong smells act as repellents and can protect the crops nearby (Dubey et al., 2011). (Singla and Parshad 2007) studied the antifeeding effects of neem-based formulation against Rattus rattus. (Kalandakanond-Thongsong et al., 2010) evaluated the efficacy of chilli, wintergreen oil, bergamot oil, peppermint oil, and geranium oil as repellents in the circular open field against adult male Wistar rats.

\subsection{Justification of the study}

Due to the negative health effect caused by chemical rodenticides, plants which are cheaper, available and environmental friendly as well as acting as a bio-rodenticides have to be investigated. This justifies the study.

\subsection{Aim/Objective of the study}

The aim of the study is to investigate the effect of Delonix regia on wistar albino rats. Specific objectives are to investigate;

(i) the phytochemical constituent of Delonix regia

(ii) the effect of Delonix Regia on the body weight,

(iii) the effect of Delonix Regia on packed cell volume

(iv) the effect on Delonix Regia on liver and kidney of wistar albino rats.

\section{LITERATURE REVIEW}

\subsection{Morphology of Delonix regia}

Delonix regia belongs to family Fabaceae, sub-family Caesalpinioideae. It is a tree which is upto 10-15m high, girth of upto $2 \mathrm{~m}$ with many branches and umbrella shaped crown. It has biparinnate, alternate, light green, feathery leaves, 10-25 pairs of pinnae and each having 12-40 pairs of small leaflets. Near the end of the twig are present $15-30 \mathrm{~cm}$ long corymbs, which are borne laterally, each having loosely arranged slightly fragrant orange-red flowers, which literally cover the tree from May to June. Petals (5-6.5 cm, 2-3 cm wide) are broadly spoon shaped. The tree is native to Madagascar and has been widely planted for the last 150 years as a garden and avenue tree in both dry and moist regions of tropical India as well as in Nigeria. It is distributed in the countries like Brazil, Burkina Faso, Cyprus, Egypt, Eritrea, Ethiopia, India, Jamaica, Kenya, Mexico, Nigeria, Singapore, South Africa, Sri Lanka, Sudan, Tanzania, Uganda and United States of America. Light is required for its growth but under shade, it grows weakly and sparsely.

It grows in areas with both high and scanty rainfall. Trees are deciduous only where the dry season is long and pronounced. There is ample literature that emphasizes the traditional use of this plant in countries such as India, Bangladesh, Zambia and Cameroon.

Though some workers have also explored its bioactivities; yet there is meager experimental evidence for its traditional use. The phytochemicals in this plant possess diverse biological activities including protection against various pathogens. The enormous significance of the phyto-constituents in Delonix regia cannot be ignored and comprehensive insight into their function in various fields and the mechanisms operating behind them is essential. Beneficial bioactivities of Delonix regia such as antifungal, antibacterial, antioxidant, antiemetic, larvicidal, hepatoprotective, anti-diarrhoeal, anti-inflammatory, antimalarial, anthelmintic, antiarthritic, wound healing and anticarcinogenic potential, along with their experimental evidence and mode of action. There are a lot of uses of Delonix regia some this uses include it use as source of traditional medicine among others. 


\title{
2.2 Uses Of Delonix Regia
}

In Shaiji community in Southwestern Bangladesh the flowers of Delonix regia is used for curing chronic fever (Halim et al.2007). During the study on the traditional medicines and herbal plants in Nigeria the flowers of Delonix regia was noted to possess antibacterial activity (Ode et al. 2011). The medicinal plants were used to cure wounds in Darikal Gaon of Tezpur, in Assam (North-East India). The leaves of Delonix regia have also been used to treat constipation, inflammation, arthritis and hemiplagia in Koothanoallur and Marakkadai, Thiruvarur district of Tamil Nadu, India (Rekha et al. 2013). The leaves and fruits are used in piles and helminthiasis in the areas of Pirojpur district, Bangladesh (Rahmatullah et al. 2010). The bark used as traditional fever remedy in Zambia (Fowler 2006). Delonix regia, an ethnomedicinal plant possessed antibacterial activity (Zahin 2010) The seeds are used in pyorrhea; the roasted and crushed leaves are wrapped in a cloth and inhaled just after scorpion bite; infusion of flowers are used in bronchitis, asthma and malarial fever. The leaves are also used in rheumatism and as purgatives. The plant has antirheumatic and sparmogenic potential. The bark showed antiperiodic, febrifuge potential; aqueous and ethanol extract of flowers were used against round worms (Khare 2007). It is also present in the list of traditional plants used by people of Bangangte region, Western Cameroon in the treatment of peptic ulcer (Noumi and Dibakto 2000). The water extracts of flowers were also used in traditional healthy beverages in several African counties.

\subsection{Biological Activities Delonix Regia}

Many biological activity have been reported of Delonix regia. These are as follows:

\subsubsection{Anti-Diarrhoeal Activity Of Delonix Regia}

The flowers of Delonix regia plant have been reported to have vivo anti-diarrhoeal activity. The experimental models used included castor oil induced diarrhea, prostaglandin E2 induced enter pooling and charcoal induced gastro intestinal motility test in Wistar albino rats. The $90 \%$ ethanolic extract of Delonix regia flower was used for activity. The flower of delonix regia shows the dose dependent antidiarrhoeal effect in all the treated groups (Shiramane et al., 2011)

\subsubsection{Anti-Inflammatory Activity of Delonix Regia}

The powdered leaves of the Delonix regia were used for the anti-inflammatory activity. The models for anti-inflammatory activity were the carrageenan-induced ran paw edema and cotton pellet granuloma. The ethanolic extract of leaves of Delonix regia shows significant activity at $400 \mathrm{mg} / \mathrm{kg}$ in the both models when compared with standard group (Shewale et al., 2011).

\subsubsection{Hepatoprotective Activity of Delonix Regia}

According to Ahmed et al., (2011) methanol extract of aerial parts of Delonix regia in CCL 4 induced liver damage rats showed that e metabolic extract of aerial parts of Delonix regia possesses hepatoprotective activity against CCL 4 induced hepatotoxicity in rat.

\subsubsection{Wound Healing Activity of Delonix Regia}

The ethanolic and aqueous extracts of Delonix regia flowers posses effective wound healing as noted in Ahmed et al., (2011) study.

\subsection{Phytochemical Constituents of Plant Extracts}

Delonix Regiaa, black pepper, curcuma long among other plant extract contain several chemical constituents such as alkaloids, tannins, flavonoids, saponins, steroids, glycosides and reducing sugars.

\begin{abstract}
Alkaloids: These are organic nitrogenous compounds that have complex molecular structures of good pharmacological activity thus, bitter in taste and mostly basic in nature (El-Olemylet al., 2010). These chemicals comprise up largest single class of secondary plant substances which contain one or more nitrogen atoms usually in combination as part of cyclic system. Alkaloids do not have an exact nomenclature but they are named as proto alkaloids, when they are without heterocyclic ring in their structures, pseudo alkaloids are those alkaloids with and without heterocyclic rings that are not derived from amino acids and the carbon skeleton is soprenoid, and true alkaloids, which are those that have heterocyclic rings in their structure. True alkaloids and photo alkaloids almost always have amino acids as their distal biosynthetic precursors and acetate is also incorporated in their structure. Alkaloids accumulate in actively growing tissues, epidermal and hypodermal cells, vascular sheath and latex vessels (Evans \& Trease, 2011).
\end{abstract}


Alkaloids are usually colourless, often optically active substance, most are crystalline but few are liquid at room temperature e.g. nicotine. The alkaloid quinine for example is one of the prodominant bitter substances known, and is significantly bitter at molar concentration of 1 X 105. The most common precursors of alkaloids are amino acids. Many alkaloids are terpenoids in nature and some (e.g Solanine, the steroidal alkaloid of the potato etc) are the best considered from the biosynthetic point of view as modified terpenoids. Others are aromatic compounds e.g. colchicines. Alkaloids are rich in the angiosperms families and are generally absent or infrequent in the gymnosperms, ferns and lower plants (Evans \& Trease, 2009).

Tannins: The term tannins denote substances present in plant extracts which are able to combine with proteins of animal hides and convert them into leather. Tannins are widely distributed in plants and occur in solution in the cell sap, often in distinct vacuoles. Tannins are readily soluble in water or alcohol, given as stringent solution that is useful in medicine. They are also used with ferric chloride in compound inks of greenish black to bluish black colours. There are two main groups of tannins; namely, true tannins and pseudo tannins. The true tannins are complex phenolic compounds. They display the general properties of tannins and are precipitated by gelatine in a $1 \%$ aqueous solution. True tannins are further classified into two main classes; hydrolysable (pyrogallol) tannins (Ellagitannin and gallitannin), and condensed tannins (catechol and catechin). The pseudo tannins (gallic and ellagic acids) are simple phenolics that give some of the tests of tannins, but are not precipitated by gelatine.

Tannins have a therapeutic value as astringents, since; they are able to precipitate proteins. Through this effect they can be used to stop haemorrhage and to treat diarrhoea as well as local burns (EL-Olemylel al., 2010).

Flavonoids: These are the largest group of naturally occurring phenols and they occur in the plant both in the free state and as glycosides. The flavonoids group may be described as a series of C6-C3-C6 compounds. The majority of flavonoids are characterized by containing linkage of the three carbon chain with one of the benzene rings. Flavonoids are widely distributed in nature, but are more common in the cell sap of higher plants. They usually constitute the yellow, red and blue pigments of flowers and fruits. Flavonoids are important in many industries such as fermentation of tea, tannins. Some flavonoids have fungicidal properties and are found to protect the plant against attack by pest and parasite (Evans and Trease, 2009).

Saponins: Saponins are one of the groups of glycosides found in many plant species with known foaming properties when mixed with water, allowing the formation of small stable bubbles. The amount of foam created by the crushed plant samples shaken with water in a jar is a good indication of the amount of saponins present. Saponins are normally broken down in the digestive system and are toxic when absorbed into the blood stream.

They are used in modern times in the manufacture of fire extinguisher foam, tooth paste, shampoos, liquid soap and cosmetics. It is also used to increase the foaming of beer soft drink. As glycosides they are hydrolysed by acids to give an agylcone (sapogenin) and various sugar and related uronin acids. The steroidal saponin and pertocyclicterpenoids have a glycosydial linkage at -C 3 and have a common biogenetic origin through malvalonic acid and isoprenoid unit (Evans and Trease, 2009).

Glycosides: Glycosides are non-reducing substances, which on hydrolysis with reagents or enzymes yield one or more reducing sugars among the products of hydrolysis. The non-sugar part of the molecule is called the agylcone or

genin, and the sugar component, the glycone. The usual linkage between the sugar and agylcone is an oxygen linkage, connecting the reducing group of a sugar and an alcoholic or phenolic hydroxyl group of the agylcone.

Such glycosides, sometimes called O-glycosides, are the most numerous ones found in nature. Other glycosides however occur, e.g. S-glycosides and $\mathrm{N}$-glycosides in S-glycosides, e.g. Sinirin, where the sugar is linked to the thiol group of the agylcone. In nglycosides (e.g. streptidine moiety of streptomycin and glucosamine), the sugar is linked to the amino group of the agylcone. There are also c-glycosides (e.g. barbalion) in which the sugar is linked to the agylcone by a carbon to carbon bond. All naturally occurring glycosides are of the $\beta$-type, although the $\alpha$-linkage is found in some carbohydrates such as sucrose, glycogen and starch (Evans and Trease, 2009).

Glycosides occur widely in nature and occur in low concentration in nearly all plants. They occur not only in angiosperms but also in lower plants e.g. in Streptomyces species. Glycosides are found in all parts of the plant, in roots, bark, leaves, flowers, fruits and seeds. Much plant pigments responsible for the colour of flowers and fruits are glycosides. Glycoside formation may well be a method of storing certain organic compounds e.g. phenols. It was also suggested that, some glycosides have a role of defence against the invasion of the tissue by micro-organisms subsequent to wounding, since many agylcones are aseptic and hence bactericidal in character. Plant glycosides that are currently used in medicine, though not larger in number, are important drugs. 
Glycosides of medicinal plants such as Delonix Regia may be used as cardial stimulants (e.g. digitoxin and quabian or laxatives) Sinnosides and barbaloin or local irritants e.g. sinigrin or analgesics (silicon) and against capillary frugility (hesperidin) (Evans and Trease, 2009).

Phytochemical analysis of extracts from root, stem and seed of plant such Delonix Regia among others show that they contain reasonable amounts of phenolic compounds including biflavonoids (GB-1,GB-2), xanthones and benzophenones (Okunjiet al., 2017; Okoko, 2009). Their antibacterial activities are due to flavonoids especially biflavonoid type GB1 (Hong-xi and Song, 2011) and this has been demonstrated using methicillin-resistant Staphylococcus aureus(MRSA), vancomycin- resistant enterococci (VRE) (Han et al., 2015), Lactobacillus spp. (Owoseni and Ogunnusi, 2016) and Streptococcuspyogenese (Ogbulie et al., 2017).

According to Afolabi et al.,( 2009) its antibacterial effects on Streptococcus mutans is another important organism involved in plaque formation. However, few reports are available on the antibacterial activities of plant on oral anaerobic species(Ndukweet al., 2015). Plant as a reservoir of effective chemotherapeutic agent can provide valuable natural drug and pesticides for effective and efficient management of human and plant disease. Some of the products of higher plants have been shown to be effective source of chemotherapeutic agent and provide renewable source anti-microbial infections of bio-degradable nature which are devoid of side effect (Farombi,2013).

Plant extracts such from Delonix Regia black pepper and curcuma long mostly contains the following chemical composition theophylline, phenolics, phlobaphens, epicatechin, D-atechin, tannic acid, sugar, cellulose and water (Sanibareet al., 2009; Anon, 2011). Some plant extract such as Kola nuts contain caffeine, which may explain their popular use of some plant extract in energy tonics and they are also thought to enhance male potency. Kola is reported to have aphrodiasic, stimulant, and cardiotonic properties (Benjamin et al., 2010). In the Kitchen, curcuma longa is an ingredient in food. It has effects similar to other xanthine containing herbs like cocoa, tea etc. However, the effect is distinctively different, producing a stronger state of euphoria and wellbeing (Benjamin et al., 2010). Some phytochemicals present acts as a bronchodilator, expanding the bronchial air passages (Jayeola, 2011; Kim, 2011). Curcuma longa, coconut and black pepper are also employed in the treatment of malaria and fever (Odugbemi, 2016). Experiments using animals indicate that some of this plant extract have analeptic and lipolytic properties and stimulate the secretion of gastric juices (GRIN,2017).

\subsection{Biochemical activities of Delonix Regia on wistar albino rat}

Rats were first used for experimental purposes in the mid 1800s. Strains were developed to study neuroanatomy, nutrition, endocrinology, genetics and behavior. The rat has short hair, a long naked tail, rounded erect ears, protruding eyes, a pointed snout with long whisker (vibrissae) and five toes on each foot. Albino rats have poor eyesight and depend on facial vibrissae and olfaction for sensory input. Rats have no gall bladder. Rattus norvegicus (brown rat) has a short tail compared to Rattus rattus (black rat), which has a much longer tail. Rats have a pair of incisors and three pairs upper and lower of molars. Molars are permanently rooted while the incisors have an open root and grow continuously. Due to this continuous growth of the incisors rats can have problems with incisor overgrowth when the upper and lower incisors do not meet properly (malocclusion). Malocclusion can be hereditary or follow trauma, disease or inappropriate diet and/or soft food. There is no permanent cure for overgrown teeth. The only treatment is to trim the teeth every 2-3 weeks, if malocclusion persists. Rats have a large horseshoe-shaped Harderian gland deep within the orbit. Secretions from the gland contain varying amount a reddish-brown porphyrin pigment depending on the physiologic state, age, strain and sex of the rat. The amount of secretions increases during stress and appears as 'red crusts' around the eyes and nostrils.

\subsection{Behavioural and reproductive Characteristic of Rat}

Rats are communal animals. Young are raised communally with shared nursing responsibilities. Males can be co housed as fighting rarely occurs among adults. Rats are burrowers and take advantage of that whenever the opportunity presented. They are nocturnal animals but adapt to their environments. Rats can inflict severe bite wounds and must be handled gently and with care to avoid biting.

\subsubsection{Reproduction}

Rats have two distinct cervices and uterine bodies. There are separate urethral and vaginal openings. There is a vaginal closure membrane, which is lost at puberty. The inguinal canal remains patent throughout life. Rats have an os penis or os clitoridis associated with external genitalia. Mammary tissue is widely distributed and may extend to the lateral and dorsal areas of the abdomen. Rats have a four to five-day estrous cycle, divided into characteristic phases: proestrus, estrus, metestrus and diestrus. The stage of the estrous cycle can be determined by vaginal cytology. Ovulation occurs at the end of metestrus. Receptive females 
exhibit lordosis when a downward pressure is applied to the pelvis. Such females will adopt a rigid posture with the hindquarters raised. Mating leads to formation of a vaginal plug. Plugs persist for 16-24 hours and may last as long as 48 hours.

\subsubsection{Rat Development}

The young rats are born incompletely developed (altricius). They are born hairless and their eyes open after 10-12 days. Young are weaned after 21 days. Puberty is attained at 7-9 weeks. Breeding onset is after 9 weeks and breeding life is 9-12 months. It may be preferable to replace breeders when they are 6-9 months old.

\subsubsection{Pregnancy}

Pregnancy lasts 21-23 days. Females will build a nest prior to parturition if opportunity is provided. Birth usually occurs at night with 10-12 pups being born. Stretching and hindleg extension are usually signs of impeding birth. Babies are born either head or tail first (breech). The female usually eats the placenta. Delivery lasts 1-4 hours, if labor persists call a veterinarian (5-3713). There is a fertile postpartum estrus. Maternal antibody is transferred to the fetus in utero and to the newborn via colostrum.

\subsection{Husbandry}

Rats are generally fed a diet containing low fiber (5\%), protein (20\%) and fat (5-10\%). Feed may be pelleted or powdered. The pelleted feed is supplied as regular, breeder, certified, irradiated or autoclavable. Rats are usually supplied feed free choice and they eat $10-30 \mathrm{~g}$ a day ( $5 \mathrm{~g} / 100 \mathrm{~g}$ body weight/day). Water is supplied free choice and they usually drink 20-50 $\mathrm{ml}$ a day (10 $\mathrm{ml} / 100 \mathrm{~g}$ body weight/day). Water may be supplied using a bottle or automatic waterers, and may be further treated by reverse osmosis, ozone, ultraviolet radiation, hyperchlorination or acidification. Rat rooms are usually maintained at 30-70\% relative humidity and a temperature of $18-26^{\circ} \mathrm{C}$ with at least 10 room air changes per hour. Rats are usually housed in standard shoebox cages with or without filter tops. Filter tops prevent cross contamination of rats limiting the spread of disease and keep facilities clean.

Cages with filter tops may have a slightly higher temperature, relative humidity, carbon dioxide and ammonia than the room air. Microisolator tops provide even a higher level of protection than bonnet type filter tops, since they seal better. Static cages as described above are usually changed one to two times a week depending on cage density and housing style. In ventilated cages air is forced into the cage at up to 60 air changes per hour. This keeps the cage dry and reduces build up of ammonia and carbon dioxide. In such situations cages are changed once every 1-2 weeks. Ventilated cages may be kept positive or negative to room air depending on the study being performed. Rats are usually provided with bedding in the shoebox cages. Bedding can be paper, wood shaving, wood chips or corncob. In very rare instances rats are housed on wire floors. Housing on wire floors must be justified and approved by the animal care and use committee.

\subsection{Identification}

Rats should always be clearly identified on cage cards indicating protocol number, strain (using standard nomenclature), sex, age, supplier, investigator and contact person. A combination of marks made by an ear punch can be used to identify rodents as indicated in the figure. Procedures performed on the animal should be clearly indicated. Individual rats can be identified using ear punches, ear tags, tattoos, fur dyes, indelible mark on tail or microchips.

\subsection{Sexing}

Sex is determined using the anogenital distance. Males have a greater (1.5-2 times) anogenital distance than females as well as a larger genital papilla. In neonatal males the testis may be visible through the abdominal wall. Conspicuous bilateral rows of nipples are visible in females at about 9 days of age. Absence of testicles is not a useful criterion for sexing since the testis is retractable throughout life into the open inguinal canal

\subsection{Handling}

Rats should be acclimatized to handling (gentling) to reduce stress. Always talk quietly, move hands slowly and handle them frequently. Rats should be handled at the base of the tail using your fingers. Pick up rats by placing the hand firmly over the back and the rib cage and restraining the head with thumb and forefinger immediately behind the mandibles. Holding the rat upside down keeps it distracted and reduces the chances of biting. A variety of restraint devices are available to assist in handling rats. Handle rats at the base of the tail, restrain head with thumb and forefinger, holding upside down reduces chances of biting 


\subsection{Blood Collection}

An adult rat has a circulating blood volume of about $15-35 \mathrm{ml}$ (5-7\% of the body weight), however in older and obese animals this may be lower. Up to $10 \%$ of the circulating blood volume may be taken on a single occasion from a normal healthy animal on an adequate plane of nutrition with minimal adverse effect. Always make sure the animal has recovered safely from the procedure and give warm isotonic fluids. This volume may be repeated after 3-4 weeks. For repeat bleeds at shorter intervals, a maximum of $1 \%$ of an animal's circulating blood volume can be removed every 24 hours. Blood can be collected from several sites in the rat including tail vein, saphenous vein, retro-orbital sinus, brachial vessels, vena cava or cardiac puncture. Always ensure complete homeostasis before returning the rat to its home cage.

\subsubsection{Tail}

It may be necessary to warm the tail by exposing it briefly to a heat lamp or placing it in a bowl of warm water. The rat should be restrained in a device for the collection. Blood can be collected from the tail vein (and artery) by making a snip in terminal $=5 \mathrm{~mm}$ of the tail with a scalpel or sharp scissors. Stroke the tail gently with thumb and finger to enhance flow of blood into the collection vial. Because of the thermoregulatory function of the tail no more than the distal $3 \mathrm{~mm}$ should be taken at a time. At the end of the collection apply pressure to the cut end with a gauze bandage and ensure that blood has completely stopped flowing before returning the rat to the cage. A small nick can also be made at side of the tail $0.5-2 \mathrm{~cm}$ from the tail base to collect blood. A fine gauge needle introduced through the skin at a shallow angle can be used to withdraw blood from the tail vein. Apply a tourniquet around the base of the tail to aid in the collection. A butterfly catheter with only about $5 \mathrm{~mm}$ of tubing attached to it (rest cut off) may be used instead of a needle and syringe.

\subsubsection{Cardiac Puncture}

Up to $10 \mathrm{ml}$ of blood can be obtained from the heart of a deeply anesthetized rat in a terminal procedure. The most common approach is to lay the rat on its back and insert a 25 to 30 gauge needle attached to a 3-5 ml syringe just behind the xiphoid cartilage and slightly left of the middle. The needle should be introduced at 10-30 degrees from the horizontal axis of the sternum in order to enter the heart. Alternatively approach the heart laterally immediately behind the elbow at the point of maximum heartbeat.

\subsection{Administration of substances}

Materials to be administered to rats can be given orally e.g. in water or feed or injected systemically through a variety of routes. The average daily consumption of feed and water for an adult rat is 15-25 $\mathrm{g}$ and 30-50 $\mathrm{ml}$ respectively. The following volumes can be injected into rats safely: 2-5 ml subcutaneously, 0.1-0.2 ml intramuscularly ( $0.1 \mathrm{ml}$ per site), 1.5-2.5 ml intravenously, 3-5 ml into the stomach and 3-5 ml intraperitonealy. Intramuscular injections are usually not recommended in rats because of the small muscle mass. A fine gauge needle should be used to make injections in the anterior thigh muscle. It is good practice to use a new needle each time you perform an injection.

\subsubsection{Gavage}

Oral gavage is performed using a ball ended feeding needle. Estimate the distance that the needle needs to be inserted into the rat (usually from the nose to the first rib) and mark it on the needle. Restrain the rat with the rat extended in a straight line to facilitate introduction of the gavage needle. Introduce the needle in the space between the left incisors and molars, and gently direct it caudally toward the right ramus of the mandible. The rat usually swallows as the feeding tube approaches the pharynx, facilitating entry into the esophagus. If the animal struggles or appears to be in respiratory difficulty withdraw the tube and begin all over again. Once the desired position is attained, inject the material and withdraw the syringe. Monitor the animal after the procedure to ensure that there are no adverse effects.

\subsubsection{Subcutaneous Injections}

Subcutaneous injections are usually made into the loose skin over the neck or flank using a fine gauge needle. Insert the needle 5$10 \mathrm{~mm}$ through the skin before making the injection. Lack of resistance to the injection is indicative that you are in the right location. Check for leak back especially if a larger volume is injected. 


\subsubsection{Intraperitoneal injections}

Intraperitoneal injections are usually made in the lower right quadrant of the abdomen. The rat is restrained with its head tilted lower than the body to avoid injury to internal organs or major blood vessels. After swabbing the lower right quadrant with alcohol, a fine gauge needle is introduced slowly through the skin, subcutaneous tissue and abdominal wall. Withdraw the syringe plunger to ensure that you are not in the bladder or intestines. If nothing is withdrawn inject the material slowly. If you accidentally enter the bladder or intestines withdraw and discard the needle and syringe.

\subsubsection{Intravenous Injections}

Intravenous injections are usually made into the dorsal tail vein. Warm the tail by immersing it in warm water or placing the animal under a heat lamp. The tail vein is easier to see in non-pigmented rats. A fine gauge needle should be used for this procedure.

\subsection{Packed cell volume (PCV)}

The haematocrit (Ht or HCT) also known as packed cell volume or erythrocyte volume fraction (EVF) is a volume percentage (\%) of red blood cells in the blood (Purves et al 2014). It is normally about $40 \%$ of women and $45 \%$ of men. It is considered as an integral part of a person's complete blood count result along with haemoglobin concentration, white blood cell count, and platelet count. In mammals hematocrit is independent of body size.

\subsubsection{Measurement of packed cell volume}

The packed cell volume (PCV) can be determined by centrifuging heparinized blood in a capillary tube (open also known as microhematocrit tube) at 10000RPM 5 minutes. This separates the blood into layers. The volume of packed red blood cells divided by the total volume of the blood sample gives the PCV because a tube is used, this can be calculated by measuring the length of the layers (Hedin et al 1891).

With modern lab equipment's, the hematocrit is calculated by an automated Analyser are not directly measured. It is determined by multiplying the red cell count by the mean cell volume. The hematocrit is slightly more accurate as the PCV includes small amount of blood plasma trapped between the red cells. An estimated amount hematocrit as a percentage may be derived by tripling the haemoglobin concentration in $\mathrm{g} / \mathrm{dL}$ and dropping the units. The haemoglobin concentration is the measure used by Blood banks to assess the level of iron in the donor's blood (hedin et al., 1891).

\subsection{Distribution and importance of albino rats}

The Norway rat, Mus norvegicus now Rattus norvegicus is the one mammal easily obtainable both wild and domesticated form Nowak in 1999 suggested that the Norway rat did not reach Europe until 1553 and the Americans until 1750. Albino rats are genetically mutated strain on brown and black currents and have played a major role in animal experimentation since its Inception Gregor Mendel reported his famous laws on mendelian inheritance in 1866 who go grandpa was the first scientist to confirm the validity of these laws in animals using some 15000 white colour Grey black and piebald rats between 1877 and 1885 the Albino rats were in fact the first animals to be domesticated for the purpose of scientific research the origin of albino rats remain unclear whether the common albino variety add a single or multiple origins or weather the colon is found in Europe are directly related to those now existing (kuramoto et al 2012).

\section{MATERIAL AND METHOD}

\subsection{Study area}

The study was conducted in Maeve Academic Research Laboratory Awka,Anambra State Nigeria.

\subsection{Collection of plant}

Freshly collected leaves of Delonix regia were gotten in front of Faculty of Agriculture at Nnamdi Azikiwe University. The plants were identified by a botanist in Nnamdi Azikiwe University before being analyzed.

\subsection{Preparation of plant sample}

Freshly collected leaves of Delonix regia were cleaned using water and it was dried under room temperature for four days then grounded into powdery form. $109.2 \mathrm{~g}$ powder of the leave was weighed and transferred into a volumetric flask where it was 
macerated with sufficient amount of ethanol for 24hours. Extracted in Soxhlet extractor using ethanol as extraction solvent, then concentrated using rotary evaporator.

\subsection{Experimental Animals}

Animals used in this study were purchased from Chris laboratory Awka and transported using a cage to Zoology animal house in Nnamdi Azikiwe University. Experiments were conducted on twenty-seven (27) healthy female albino rats weighing about 66g133g. The rats were kept in an aluminum cages with beddings of clean wood shavings in a well-ventilated house at maintained at room temperature $\left(26 \pm 1^{\circ} \mathrm{C}\right)$ and 12 hours light/dark cycles till the end of the experiment. Before each test, the rats were fasted for at least 12 hours. All the animals had a free access to conventional laboratory rodent pellet diet standard for biomedical researches and a drunken water taps ad libitum. The rats were acclimatized to the Zoology animal house condition for One week prior to the experimental protocol to minimize any nonspecific stress.

\subsection{Procedure for Phytochemical Screening}

Major metabolites classes such as alkaloids, Cardiac glycoside, Anthraquinone glycosides, flavonoids, Tannins, saponins, steroids and terpenes were screened according to the methods described by a guide to modern techniques of plant analysis, Medicinal Plants and Traditional Medicine in Africa and Pharmacognosy (Harborne,1973).

Test For Phenol(Method of Harborne,1973): Two millilitre( $2 \mathrm{ml})$ of the extract was pipette into a test tube, few drops of dilute ferric chloride solution is added. The formation of a red, blue, green, or purple coloration indicates the presence of phenols.

Test for Alkaloids (Method of Harborne,1973): Two millilitre(2ml) of the extract was pipette into a test tube The filtrate was carefully tested with Mayer's reagent(potassium mercuric iodide). yellow coloured precipitate indicates the presence of alkaloids.

Cardiac glycoside (Method of Harborne,1973):Keller-Killani test- To Two millilitre(2ml) of extract, few drops of glacial acetic acid was added, few drop $10 \%$ ferric chloride and concentrated sulphuric acid were added. Appearance of reddish brown colour at the junction of the two liquid layers indicates the presence of cardiac glycosides.

Anthraquinone glycosides (Method of Harborne,1973): Borntrager's Test - To Two millilitre(2ml) extract dilute sulphuric acid was added, boiled and filtered. To the cold filtrate equal volume benzene or chloroform was added. The organic layer was separated and ammonia was added. Ammonia layer turns pink or red.

Test for Flavonoids(Method of Trease,1999).To Two millilitre(2ml) of extract, few drops ammonia solution was added. Appearance of yellow or orange color indicates the presence of flavonoids.

Test for Tannins( Method Evans \& Sofowora, 1993): To Two millilitre(2ml) water extract of all plant parts, $2 \mathrm{ml}$ of $10 \%$ ferric chloride solution was added in a test tube. Blue-black precipitate indicates the presence of tannins.

Test for Saponin: To Two millilitre( $2 \mathrm{ml})$ extract of the plant sample Two millilitre( $2 \mathrm{ml})$ distilled water was added in a test tube and vigorously shaken. Persistent froth volume or bubbles produced indicates the presence of saponin.

\section{Test for Steroids and Terpenes (Liebermann-Burchard reaction)}

To $2 \mathrm{ml}$ extract of the samples, $2 \mathrm{ml}$ acetic anhydride and few drops concentrated sulphuric acid were added in a test tube. Bluegreen ring between layers indicates the presence of steroids and pink- purple ring indicates the presence of terpenes

\subsection{Application of Plant Extract on Experimental Albino Rat}

Experimental albino rats were divided into three groups A, B and C consisting of 9 rats with 3 replicates each. Group A were give $200 \mathrm{mg} / \mathrm{ml}$ dosage of plant extract, group B were given $400 \mathrm{mg} / \mathrm{ml} \mathrm{dosage} \mathrm{of} \mathrm{the} \mathrm{plant} \mathrm{extract} \mathrm{while} \mathrm{group} \mathrm{C} \mathrm{were} \mathrm{used} \mathrm{as} \mathrm{the}$ control experiment. The treatment was given to the experimental rats for 10days.

\subsection{Hematology study}

The hematology indices that was studies included only package cell volume which is also called blood count. This was done using W.H.O (2013) method.in carrying this out, $1 \mathrm{ml}$ blood sample was collected from the albino rat and transferred into capillary tube then centrifuge at 200rmp for 5minutes. The ration of whole blood to blood plasma was read using hematocrit reader then recorded accordingly. 


\subsection{Toxicology Evaluation}

Experimental albino rats were observed for sign and symptoms such as weakness, dizziness, death among others then recorded accordingly. Acute toxicity was then calculated at LD200 and LD400 using the arithmetic method of Karber (1931) as shown below .

$\mathrm{LD} 50=\mathrm{LD} 100-\Sigma(a \times b) n$

Where

$n=$ total number of animal in a group.

$a=$ the difference between two successive doses of administered extract/substance.

$b=$ the average number of dead animals in two successive doses.

LD100 $=$ Lethal dose causing the $100 \%$ death of all test animals.

\subsection{Histopathology study}

Relative Organ weights : Experimental albino rats organ analysis were done by examining the vital organs (liver and kidneys) . The vital organs were excised, cleaned of blood, weighed and examined microscopically for ulceration or any abnormalities and their relative weights calculated as: Relative organ weight - ROW $(\%)=$ weight of organ / body weight of rat $\times 100$.

\subsection{Statistical Analysis}

The data collected were subjected to one-way analysis of variance (ANOVA) to ascertain the level of toxicity significance of the treatment given at $0.05 \%$.. Sigma plot statistical software package version 12 was used to run ANOVA analysis.

\section{RESULT}

The result of the study were presented in table and interpreted accordingly as shown below.

Table 1: Comparison of body weight before and after treatment of Delonix regia extract on albino rats

\begin{tabular}{|c|c|c|c|c|}
\hline Group & $\begin{array}{l}\text { Replica } \\
\text { te }\end{array}$ & $\begin{array}{l}\text { Weight Before } \\
\text { Treatment(g) }\end{array}$ & $\begin{array}{lr}\text { Weight } & \text { after } \\
\text { treatment } & \text { at } \\
(200 \mathrm{mg} / \mathrm{ml}) & \end{array}$ & $\begin{array}{l}\text { Weight after treat at } \\
\text { 400mg }\end{array}$ \\
\hline $\mathrm{A}$ & $\begin{array}{l}\text { R1 } \\
\text { R2 } \\
\text { R3 }\end{array}$ & $\begin{array}{l}114 \\
101 \\
129 \\
\mathbf{x}=\mathbf{1 1 4 . 6 6} \pm \mathbf{8 . 0 8}^{\mathbf{a}}\end{array}$ & $\begin{array}{l}124 \\
118 \\
143 \\
\mathbf{x}=\mathbf{1 2 8 . 3 3} \pm \mathbf{7 . 5 3}\end{array}$ & $\begin{array}{l}114 \\
109 \\
135 \\
\mathbf{X}={\mathbf{1 1 9 . 3 3} \pm \mathbf{7 . 9 6 5}^{\mathbf{a}}}\end{array}$ \\
\hline B & $\begin{array}{l}\text { R1 } \\
\text { R2 } \\
\text { R3 }\end{array}$ & $\begin{array}{l}91 \\
98 \\
95 \\
\mathbf{X}=\mathbf{9 4 . 6 6} \pm \mathbf{2 . 0 2}\end{array}$ & $\begin{array}{l}124 \\
118 \\
143 \\
\mathbf{X}=\mathbf{1 2 8 . 3 3} \pm \mathbf{7 . 5 3 5}\end{array}$ & $\begin{array}{l}114 \\
109 \\
135 \\
\mathbf{X}=\mathbf{1 1 9 . 3 3} \pm \mathbf{7 . 9 6}^{\mathrm{a}}\end{array}$ \\
\hline $\mathrm{C}$ & $\begin{array}{l}\text { R1 } \\
\text { R2 } \\
\text { R3 }\end{array}$ & $\begin{array}{l}83 \\
114 \\
82 \\
\mathbf{X}=\mathbf{9 3 . 0 0} \pm \mathbf{1 0 . 5 0 a}\end{array}$ & & \\
\hline
\end{tabular}

\section{R1- R3 =replicate}

Rows with subscript ${ }^{\mathbf{b}}$ is statistically significant while that with ${ }^{\mathbf{a}}$ is not statistically significant.

Table 1 shows that the mean value before treatment is $114.66 \pm 8.08$, and after treatment it increased to $128.33 \pm 7.53$ at $200 \mathrm{mg} / \mathrm{ml}$. while that of treatment at $400 \mathrm{mg} / \mathrm{ml}$ is $119.33 \pm 7.965$ after treatment. Comparing the mean weight value, the mean weight of 
$200 \mathrm{mg} / \mathrm{ml}$ treatment is higher than the mean weight before treatment and that of $400 \mathrm{mg} / \mathrm{ml}$ weight. On the other hand, that of $400 \mathrm{mg} / \mathrm{ml}$ treatment is more than that of weight before treatment. This result is an indication that the treatment has impact on the body weight of the rats in group A.

For group B rate, mean weight is $94.66 \pm 2.02$, weight of after treatment at $200 \mathrm{mg} / \mathrm{ml}$ dose of the extract is $128.33 \pm 7.535$, that of treatment at $400 \mathrm{mg} / \mathrm{ml}$ is $119.33 \pm 7.96$. Mean weight of $200 \mathrm{mg} / \mathrm{ml}$ treatment is higher than that of $400 \mathrm{mg} / \mathrm{ml}$ and the mean weight before treatment. The mean weight of group $\mathrm{C}$ which is the control experiment is $93.00 \pm 10.50$. Comparing this weight to the weight of treatment at $200 \mathrm{mg} / \mathrm{ml}$ and $400 \mathrm{mg} / \mathrm{ml}$, there is a clear indication that the mean weight of treated are all higher than that of the control. This implies that the weight of the rat increased due to the treatment given.

Table 2. Packed Cell Volume

\begin{tabular}{|c|c|c|c|c|}
\hline Replicate & $200 \mathrm{mg} / \mathrm{ml}$ & $400 \mathrm{mg} / \mathrm{ml}$ & control & Pcv normal range \\
\hline R1 & 46 & 35 & 37 & 37.6 \\
\hline $\mathrm{R} 2$ & 50 & 26 & 35 & 37.6 \\
\hline \multirow[t]{2}{*}{ R3 } & 35 & 30 & 35 & 37.6 \\
\hline & $X=43.66 \pm 4.48^{b}$ & $X=30.33 \pm 2.603^{a}$ & $X=35.66 \pm 0.66$ & $37.66 \pm 0.00-50 \pm 0.00$ \\
\hline
\end{tabular}

Row with subscript ${ }^{\mathbf{b}}$ is statistically significant.

Table 2 shows that the mean PCV value for $200 \mathrm{mg} / \mathrm{ml}$ is $43.66 \pm 4.48^{\mathbf{b}}$, that of $400 \mathrm{mg} / \mathrm{ml}$ is $30.33 \pm 2.603$ and control is $35.66 \pm 0.66$. When Compared to acceptable range, only rats given dosage of $200 \mathrm{mg} / \mathrm{ml}$ treatment have PCV within the acceptable range. The mean PCV value for $400 \mathrm{mg} / \mathrm{l}$ is less than the acceptable range as well as that of the control.

TABLE 3: ONE Way ANOVA COMPARISON BETWEEN 200mg/ml And 400mg/ml

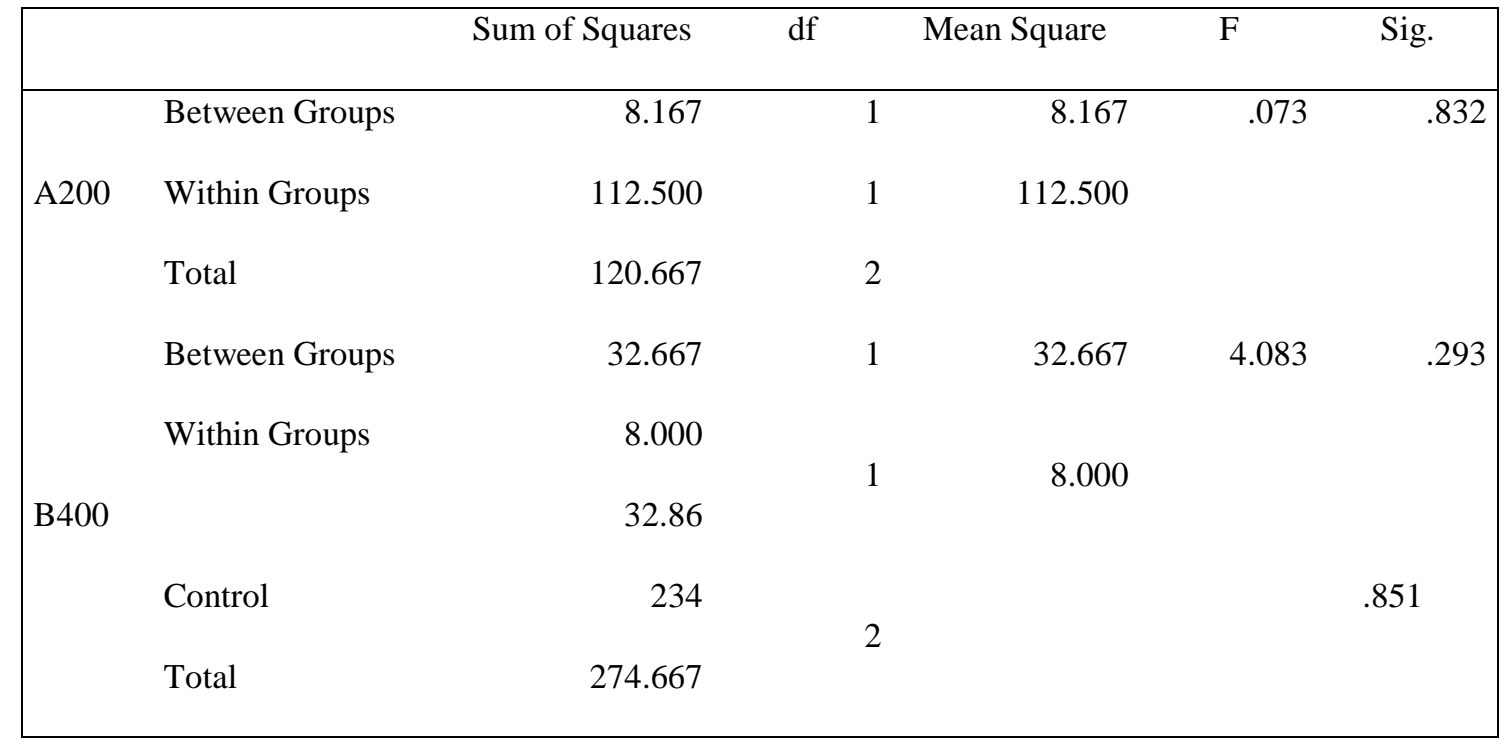

Table 3 shows that between $200 \mathrm{mg} / \mathrm{l}$ and $400 \mathrm{mg} / \mathrm{l}$ there is no real statistical difference in their PCV value at $\mathrm{P}>0.05 \%$.

\subsection{Toxicology Evaluation}

Within the ten days ( one week three days) which the Experiment was conducted, there were no mortality of the albino rats and no physical signs of weakness, dizziness, among other toxic signs observed at lethal dose of 200(LD200) and 400(LD400) respectively for the two experimental group given treatment of Delonix regia extract at 200mg/ml and 400mg/ml respectively. 
International Journal of Research in Agriculture, Biology \& Environment (ijagri), Vol. 2 (1), Jan-March - 2021

\subsection{Histology Evaluation}

Table 4.2.1 Organ weights

\begin{tabular}{|c|c|c|c|c|}
\hline Organ & $\begin{array}{l}\text { Group A Weight on } \\
200 \mathrm{mg} / \mathrm{ml} \text { treatment }\end{array}$ & $\begin{array}{lll}\text { Group } & \text { B } & \text { Weight } \\
\text { on } & 400 \mathrm{mg} / \mathrm{ml} \\
\text { treatment } & \end{array}$ & $\begin{array}{l}\text { Weight of control } \\
\text { Experiment }\end{array}$ & $\begin{array}{l}\text { Rang for albino } \\
\text { Tyre rat strain }\end{array}$ \\
\hline Liver & $4.4 \mathrm{~g}$ & $4.2 \mathrm{~g}$ & $2.9 \mathrm{~g}$ & $5.87 \mathrm{~g}$ \\
\hline kidney & $0.8 \mathrm{~g}$ & $0.9 \mathrm{~g}$ & $0.4 \mathrm{~g}$ & $1.397 \mathrm{~g}$ \\
\hline $\begin{array}{l}\text { Relative organ weight } \\
\text { of Liver }\end{array}$ & $3.55 \%$ & $3.68 \%$ & $2.64 \%$ & $3.173 \%$ \\
\hline $\begin{array}{l}\text { Relative organ weight } \\
\text { of kidney }\end{array}$ & $0.65 \%$ & $0.79 \%$ & $0.36 \%$ & $0.758 \%$ \\
\hline
\end{tabular}

Table 3 shows that the liver and kidney weight of group A given $200 \mathrm{mg} / \mathrm{ml}$ dosage of treatment are $4.4 \mathrm{~g}$ and $0.8 \mathrm{~g}$ respectively and are greater than the control experimental weight of $2.9 \mathrm{~g}$ and $0.4 \mathrm{~g}$ respectively for liver and kidney weight. Relative organ weight of the liver for group A is $3.55 \%$, that of group B is $3.68 \%$ while that of experimental control is $2.54 \%$. Comparing the organ weights of the both group to the standard range it can be seen that both the liver and the kidney for both groups are within the acceptable range of limit. The relative organ weight for the kidney for group A is $0.65 \%$, for group B is $0.79 \%$ while for control is $0.36 \%$. These values for both group A and B are also within the acceptable range from the result, the organ weight of group A given $200 \mathrm{mg} / \mathrm{ml}$ dose of Delonix regia are all lesser than that of organ weight of rat given $400 \mathrm{mg} / \mathrm{ml}$ dosage. On the other hand, the organ weights for group A and B are all greater than that of the control experiment. This implies that the treatment all had an effect on the organ weight of the albino rat.

Table 4.2.2 :Phytochemical constituent of Delonix regia

\begin{tabular}{cc}
\hline Phytochemical & Present(+) absent (-) \\
\hline Alkaloid & + \\
Anthraquinone glycoside & - \\
Cardiac glycoside & + \\
Flavonoid & + \\
Phenol & + \\
Saponnin & + \\
Steroid & + \\
Terpenes & - \\
\hline
\end{tabular}

Table 4.2.3 shows that Delonix regia extract contain phytochemical such as alkaloid, cardiac glycoside, flavonoid, phenol, saponnin, steroid but do not contain anthraquinone glycoside and terpene. 
International Journal of Research in Agriculture, Biology \& Environment (ijagri), Vol. 2 (1), Jan-March - 2021

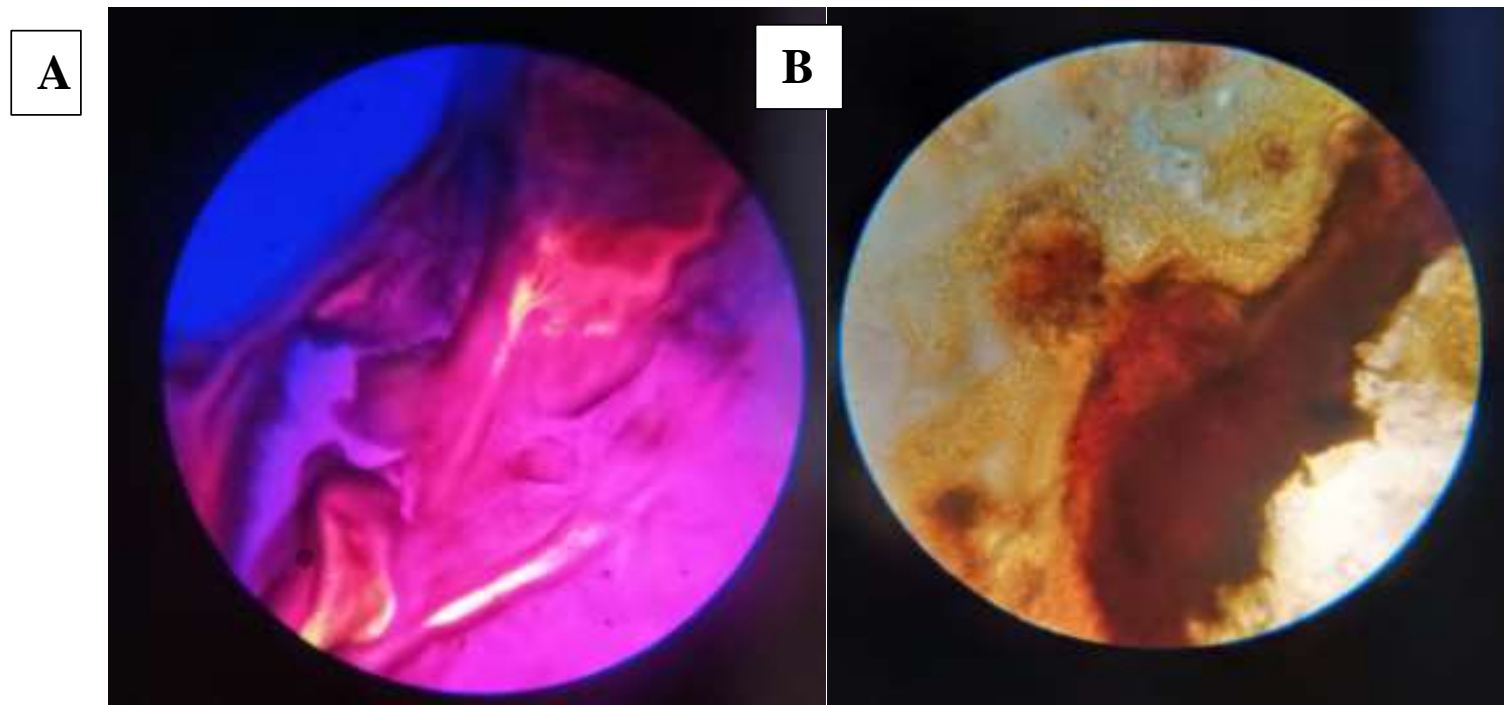

A:Liver of Group Given 200mg/ml(10X) :B: Liver of group given 400mg/ml(10X)

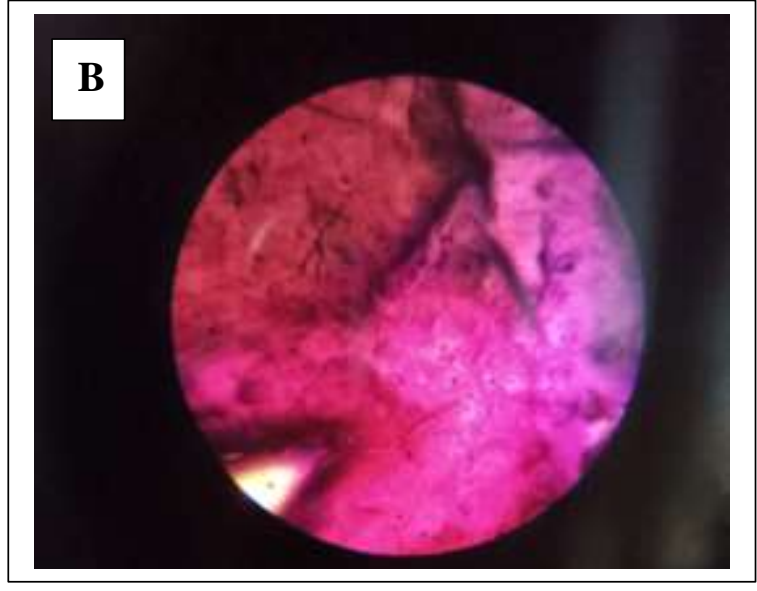

Kidney of Group Given 200mg/ml(10X)

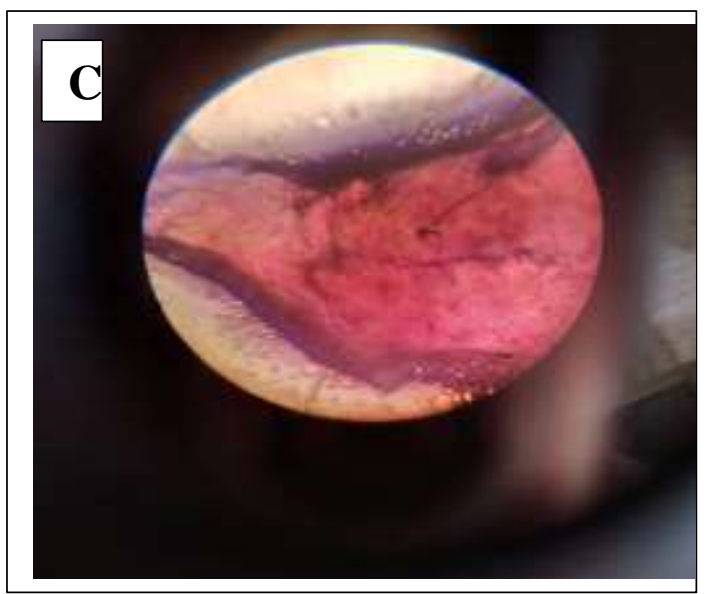

Kidney of Group Given 400mg/ml(10X)

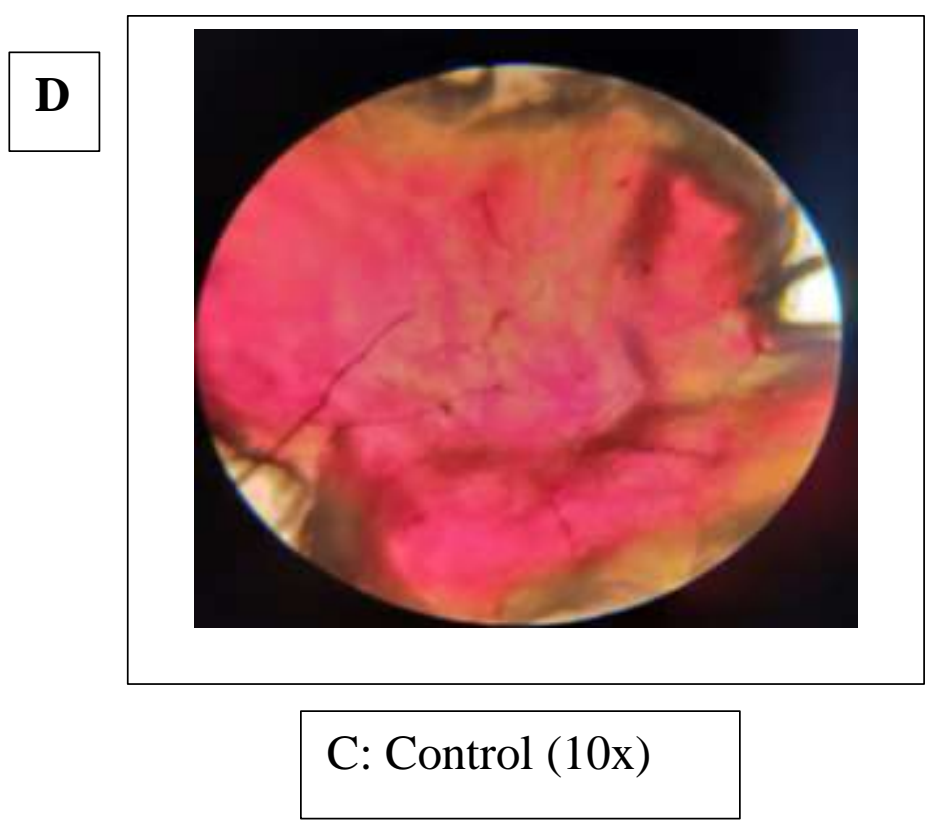




\section{DISCUSSION, CONCLUSION AND RECOMMENDATION}

\subsection{Discussion}

The finding from the study indicated that Delonix regia extract at $200 \mathrm{mg} / \mathrm{ml}$ increases the body weight of albino rat but at higher concentration of $400 \mathrm{mg} / \mathrm{ml}$, the extract reduces the body weight of the rats. This implies that at lower dosage, the Delonix regia extract gives better result as compared to when it is administered at high dosage. High dosage of $400 \mathrm{mg} / \mathrm{ml}$ also have a deteriorating effect on the blood count known as packed cell volume while at the dosage of $200 \mathrm{mg} / \mathrm{ml}$, the blood count is not reduced but maintained at the acceptable medical range needed for good growth and development of the rat. It was also noted from the finding of the study that Delonix regia extract contain phytochemical such as alkaloid, cardiac glycoside, flavonoid, phenol, saponnin, steroid while anthraquinone glycoside and terpene are absent. This finding agree with the finding of Ode et al. (2011) who in his study reported that Delonix regia contain phytochemicals which have antibacterial activities and contribute to good health.

It was also noted from the findings of the study that both organ weight and relative organ weight of rat given treatment dose of $200 \mathrm{mg} / \mathrm{ml}$ out performed well in weight as compared to the organ relative weight of the experimental control and that of $400 \mathrm{mg} / \mathrm{ml}$ dosage. This also suggests that at high concentration of Delonix regia extract, the organ weight of rat is reduced while at $200 \mathrm{mg} / \mathrm{ml}$ organ weight increases. This means that at lower dosage of the extract, the level of toxicity is inconsequential but at higher dosage, it has some level of consequence on the health of the albino rat. This finding corroborate with the finding of Ahmed et al., (2011) who reported that methanol extract of aerial parts of Delonix regia in CCL 4 induced liver damage rats showed that e metabolic extract of aerial parts of Delonix regia possesses hepatoprotective activity against CCL 4 induced hepatotoxicity in rat. The finding also agree with the finding of Ahmed et al., (2011) who also said that ethanolic and aqueous extracts of Delonix regia flowers possess effective wound healing.

The finding also showed that when at lower dose of $200 \mathrm{mg} / \mathrm{ml}$ and as well as at $400 \mathrm{mg} / \mathrm{ml}$ there is no sign of toxicity that are easily noticed physically with respect to toxic signs like body weakness, dizziness among others. Therefore, it may be inferred that toxicity of Delonix regia extract can only be physically noticed at higher dosage above $400 \mathrm{mg} / \mathrm{ml}$. From the toxicology evaluation, findings showed that at $200 \mathrm{mg} / \mathrm{ml}$ and $400 \mathrm{ml} / \mathrm{ml}$, there are no lethal effect on the rat.

\subsection{Conclusion}

Evidence from the study has shown that Delonix regia extract at lower dosage do not have any significant implication for rat and as well on man when consumed. Rather it contributes to the wellbeing of the organism that utilizes the Delonix regia extract. But on the other hand, when Delonix regia extract is being consumed at high dosage, it has a significant negative impact on the packed cell volume as well as on the organ weight and general body weight. This means that a lower dosage of it is far more better than higher dose. Hence, the need of adequate care when being injected either orally or through any means into the body.

\section{2: Recommendation}

Based on the findings of the study, the followings are recommended .

1. Pharmaceutical industries should harness the potential of Delonix regia extract in the production of drugs and use it in the control of obesity among human population.

2. Little dosage of the Delonix regia extract can be also be used in other to boast and maintain packed cell volume.

\section{REFERENCES}

Arjariya A and Chaurasia K.(2009) Some medicinal plants among the tribes of Chhatarpur district (M. P) India. Ecoprint 16:4350.

Bonnefoy, X., Kampen, H. and Sweeney, K. (2008). Public health significance of urban pests. WHO, Copenhagen: 1-56920) Buckle, A., Prescott, C., Ward, K. (1994). Resistance to the first and second generation anticoagulant rodenticides-a new perspective. In: Halverson WS, Crabb AC (eds) Proceedings of the 16th Vertebrate Pest Conference, Santa Clara. University of California, pp 138-141

Cameron, T. (1949) Diseases carried by house mice. Canadian Journal Camp Med Vet Sci 13:262 
Dubey, N. K Shukla, R. Kumar, A. Singh, P. and. Prakash, B(2011) Global scenario on the application of natural products in integrated pest management programmes," in Natural Products in Plant Pest Management, N. K. Dubey, Ed., CAB International. 1: 1-20.

Fowler DG.( 2006. ) Traditional fever remedies: a list of Zambian plants; p. 18.

Geduhn, A., Esther, A., Schenke, D., Mattes, H., Jacob, J. (2014). Spatial and temporal exposure patterns in non-target small mammals during brodifacoum rat control. Sci Total Environ 496:328-338

Hadler, M.R. and Buckle, A.P. (1992). Forty five years of anticoagulant rodenticides—past, present and future trends. In: Borrecco JE, Marsh RE (eds) Proceedings of the 15th Vertebrate Pest Conference, Newport Beach. University of California, pp 149-155

Halim, M..A.., Chowdhury, M..S.H.., Wadud, A.I., Uddin ,M.S., Sarker, S.K. and Uddin M.B. (2007). The use of plants in traditional health care practice of the Shaiji community in Southwestern Bangladesh. Journal of Trop Forest Science 19:16875.

Kalandakanond- S. Thongsong, S. Daendee, B. Thongsong, and V. Chavananikul(2010), “The efficacy of pure natural repellents on rat responses using circular open field," Thai Journal of Veterinary Medicine, 40(4): 411-418.

Khare C.P.(2007) (Ed.). Indian Medicinal Plants-An Illustrated Dictionary. Springer, New York, USA. p. 205-6.

Noumi E.and Dibakto T.W.(2000) Medicinal plants used for peptic ulcer in the Bangangte region, Western Cameroon. Fitoterapia 71

Ode, O.J., Saka, S. and Oladele G..M. (2011). The global relevance of traditional medicine and herbal plants, the nigerian perspective. International Journals of Applied Biol Pharm Technology 2:280-9.

Rahmatullah ,M., Haque, M.R.., Kamrul Islam, S., Jamal F., Anwarul Bashar A.B.M andAhmed,(2010). A Survey on the use of medicinal plants by folk medicinal practitioners in three areas of pirojpur district, bangladesh. American-Eurasian Journal Sustain Agric 4:247-59.

Rekha, D., Tamil, S.S., Bharathidasan, R., Panneerselvam, A., Ilakkiya, R. and Jayapal R. (2013). Study of medicinal plants used from koothanoallur and Marakkadai, Thiruvarur district of Tamil Nadu, India. Hygeia. Journal of Drugs Med 5:164-70.

Singla N. and Babbar B.K.(2010). Rodent damage and infestation in wheat and rice crop field: district wise analysis in Punjab State," Indian Journal of Ecology, 37( 2): 184-188.

Singla, L. D., Singla, N., Parshad, V. R., Juyal, P. D. and Sood, K. (2008). "Rodents as reservoir of parasites in India," Integrative Zoology, 3,(1): 21-26.

Singla, N and Parshad, V. R,(2007) "Antifeeding effects of a neem (Azadirachta indica)-based formulation botanical bird repellent against the house rat (Rattus rattus)," Indian Journal of Agricultural Sciences, 77, ( 8): $502-504$.

Singleton G. R. and Redhead, T. D.(1989). “House mouse plaguesin," in Mediterranean Landscapes in Australia-Mallee Ecosystems and Their Management, J. C. Noble and R. A. Bradstock, Eds., CSIRO, Melbourne, Australia. pp. $418-433$.

Singleton, G..R., Belmain, S, Brown, P.R and Hardy B (2010) Rodent outbreaks: ecology and impacts. International Rice Research Institute, Los Baños Pp225-238

Singleton, G..R.., Brown, P.R., Jacob, J., Aplin, K. and Sudarmaji (2007). Unwanted and unintended effects of culling-a case for ecologically-based rodent management. Integrated Zoology 2:247-259.

Tripathi, P.. Dubey, N. K and. Shukla, A. K(2008) "Use of some essential oils as post-harvest botanical fungicides in the management of grey mould of grapes caused by Botrytis cinerea," World Journal of Microbiology and Biotechnology, 24,(1): 39-46.

Zahin, M., Aqil, F., Khan, M.S.A and Ahmad I. (2010). Ethnomedicinal plants derived antibacterials and their prospects, in: Chattopadhyay D. (Ed.), Ethnomedicine: A Source of Complementary Therapeutics. Research Signpost, Kerala, India. p. 149-78. 
Afolabi O. B. Nwantiti, A.O and Okafor, N. (2009). The chemical basis of the pathology of yam tuber. In: Advances in yam research: the biochemistry and technology of yam tuber (ed. Osuji, G.). Biochemical Soc. Of Nigeria in collaboration with Anambra State University of Technology, Nigeria pp.249-258.

Odugbemi, O.I(2016) Identification and Pathogenicity of Rot-Causing Fungal Pathogens Associated with Xanthosoma sagittifolium Spoilage in South Eastern Nigeria. International Journal of Agriculture Innovations and Research, 2 (6): 2319-1473.

GRIN,H(2017).). Effect of annealing and heat moisture conditioning on the physiochemical characteristics of Bambara groundnut Voandzeia substerran starch. Nahrung/Food, 46, $311-316$.

Kim, C(2011). Mycological Deterioration and Pathogenicity Studies of Post-harvest Cassava. Food Science and Technology, 4 (2): 23-30.

Jayeola, D(2011)Fungi Associated with the Post-Harvest Loss of Sweet Potato. International Journal of Research Studies in Biosciences, 3 (9): 32-37

Anon,R( 2011) Fungi Associated with the storage Rot yam (Dioscorea rotundata Poir) in Yola, Adamawa state. Jour. of Sustainable Dev. In Agric. and Environ. 3(2):99-103.

Benjamin ,H,Asumugha, K. and Mbanaso, I. (2010), An assessment of the microbiological safety of dry yam processed in south West Nigeria, Africa Journal of Biotechnology, 6:157-161.

Sanibareet, E,Borate, R.N. and Nwakamma, P.T. (2009). Biodegradation of white yam (Dioscorea rotundata poir) and water yam (Dioscorea alata L.) slices dried under different conditions. KMITL Sci \& Tech. Journal. 5(3):577-586.

Okoko, F(2009). Roles of Fungal Rots in Post-Harvest Storage Losses in some Nigerian varieties of Dioscorea species. British Microbiology Research Journal. 4 (3): 343-350.

El-Olemylet al,L,Chinen-chun, B.A. and Chukunda, F.A. (2010). Influence of some macro-elements, moisture and oxalic acid on rot of Cocoyam (Colocasia and Xanthosoma species). Int'l J. Crop Science 3(1): 10 - 14

Evans,E and Trease,B (2011). Assessment of Cassava Root and stem Rots in Ecozones of Togo and Evaluation of the Pathogen Virulence. Pak. Journal Bot. 42(3): 2059-2068.

Owoseni,M and Ogunnusi,G (2016)Cytogenetic techniques. In: Onyeike EN, Osuji JO (eds.) Res. Techniques in Biology. and Chem. Sci. Spring field Publishers Ltd., Owerri, Nig. pp. 70-83.

El-Olemyl, B.A; Adeniji, M.O; Zuofa, K. and Daniel-Kalio, L.A. (2010), Root and Corm rot of Cocoyams and Susceptibility of four cultivars of Cocoyams (Xanthosoma and Colocasia species) to microbial decay on Rivers State, Nigeria. African J. Root and Tuber Crops 3(1): 1-3

Okunjie,O,Esquenazi, R.C.I and Maduewesi, J.N.C (2017). Variability in pathogenicity of isolate and sensitivity to Benlate, Diathane M. 45. and PCNB of cocoyam rot fungi: Nig. J. of Plant Prot. 9: 74-81.

Ndukweet,R,Ewanishi, O. and Obetta, J. A.N. (2015). Fungi Associated with storage rots of cocoyams (Colocasia spp.) in Nsukka, Nigeria. Mycopathologia, 134: 21-25. 